Review article

\title{
A survey on applying machine learning techniques for management of diseases
}

\author{
Enas M.F. El Houby* \\ National Research Centre, Systems and Information Department, Engineering Division, Cairo, Egypt
}

\section{A R T I C L E I N F O}

\section{Article history:}

Received 30 September 2017

Received in revised form 2 December 2017

Accepted 11 January 2018

Available online 19 January 2018

\section{Keywords:}

Data mining

K-nearest neighbour

Decision tree

Artificial neural network

Associative classification

\section{A B S T R A C T}

During the past years, the increase in scientific knowledge and the massive data production have caused an exponential growth in databases and repositories. Biomedical domain represents one of the rich data domains. An extensive amount of biomedical data is currently available, ranging from details of clinical symptoms to various types of biochemical data and outputs of imaging devices. Manually extracting biomedical patterns from data and transforming them into machine-understandable knowledge is a difficult task because biomedical domain comprises huge, dynamic, and complicated knowledge. Data mining is capable of improving the quality of extracting biomedical patterns.

In this research, an overview of the applications of data mining on the management of diseases is presented. The main focus is to investigate machine learning techniques (MLT) which are widely used to predict, prognose and treat important frequent diseases such as cancers, hepatitis and heart diseases. The techniques namely Artificial Neural Network, K-Nearest Neighbour, Decision Tree, and Associative Classification are illustrated and analyzed. This survey provides a general analysis of the current status of management of diseases using MLT. The achieved accuracy of the various applications ranged from $70 \%$ to $100 \%$ according to the disease, the solved problem, and the used data and technique.

(C) 2018 Faculty of Health and Social Sciences, University of South Bohemia in Ceske Budejovice. Published by Elsevier Sp. z o.o. All rights reserved.

\section{Introduction}

The past few years have witnessed an increasing of data in all fields and of almost all types. Biomedical data specifically have increased dramatically in the past years because of the exponential growth of knowledge in biomedical domain. The amounts of data generated by healthcare transactions are too complex and huge to be processed and analyzed by traditional methods. This data often hide valuable knowledge. Biomedical researchers face a problem of finding important knowledge from this huge amount of data. So health informatics is a rapidly growing field that is concerned with applying computer science and information technology to medical and health data (Brin, 1998; Huang et al., 2006).

Health informatics is the field of information science concerned with the analysis, use and dissemination of medical data and information through the application of computers to various

\footnotetext{
* Author for correspondence to: National Research Centre, Systems and Information Department, Engineering Division, El Buhouth Street, Dokki, Cairo, Egypt.

E-mail addresses: enas_mfahmy@yahoo.com,em.fahmy@nrc.sci.eg (E.M.F. El Houby).
}

aspects of health care and medicine (National Library of Medicine, 2017). Health informatics is defined as "all aspects of understanding and promoting the effective organization, analysis, management, and use of information in health care." It involves the use of informatics in the discovery and management of new knowledge relating to health and disease (American Medical Informatics Association, 2017). Appropriate computer-based systems and efficient analytical methodologies can help to discover important hidden knowledge from huge medical databases. So in present era, data mining is becoming popular in healthcare field.

Data mining (DM) provides the methodology and technology to transform mounds of data into useful information for decision making. Data mining is defined as "a process of nontrivial extraction of implicit, previously unknown and potentially useful information from the data stored in a database". It is the core step of a broader process, called knowledge discovery in databases. This process includes the application of several pre-processing methods aimed at facilitating the application of the DM algorithm and post processing methods aimed at refining and improving the discovered knowledge (Freitas, 2003).

Building prediction models from various medical data sources is possible using a knowledge discovery in data or DM approach based on different MLTs and the prediction accuracy of the resulted 
intelligent systems could even reach high accuracy. It is the process of finding correlations or patterns among different fields in large medical databases. Application of DM in the medical field can be used to analyze and find hidden patterns inside patients' datasets or medical databases.

Motivated by the world-wide increasing mortality of cancer, hepatitis and heart disease patients each year and the availability of huge amount of patients' data that could be used to extract useful knowledge, researchers have been using DM to help health care professionals in the management of these disease (Helma et al., 2000). In this research, an overview of the current researches being carried out using Artificial Neural Network (ANN), K-Nearest Neighbour (K-NN), Decision Tree (DT), and Associative Classification (AC) for diagnosis, prognosis and treatment of these diseases is presented. The rest of this research is organized as follows: First an overview of the techniques and diseases which are focused in this study is introduced in the Background section. The used methodology and extracted data from literature review is presented in the Materials and methods section. The results analysis of extracted data is presented in the results section. And finally the conclusions and discussion are presented in the Discussion and Conclusion section.

\section{Background}

Data mining in healthcare is field of high importance attempts to solve real world health problems such as a deeper understanding of medical data and the prediction of diseases (Liao and Lee, 2002). Researchers are using DM in the prediction of several diseases such as diabetes, stroke, cancer, and heart disease. Several DM techniques or the so called MLT such as Naïve Bayes, Decision Tree, neural network, genetic algorithm, and support vector machine when used showed different levels of accuracies.

Cancer, Hepatitis, and cardiovascular diseases are among the most serious and diverse diseases. The amount of data coming from instrumental and clinical analysis of these diseases is quite large and therefore the development of tools to facilitate management of these diseases is of great importance. Also since that the MLTs which have been used in biomedical domain are found to be too many and applied on many diseases. So, in this research the focus will be on the application of some important techniques which are ANN, K-NN, DT, and $A C$ to the field of management of these diseases. In the next subsections, an overview of these adopted diseases and the selected MLTs will be given.

\section{The adopted diseases}

The application of data mining on different diseases is rapidly spreading, in this review Hepatitis, Cancers and heart diseases will be tackled as widely spread diseases all over the world and increasing mortality diseases according to World Health Organization (WHO).

\section{Heart or cardiovascular diseases (CVDs)}

Heart disease is the leading cause of death in the world over the past 10 years. An estimated 17.5 million people died from CVDs in 2012, representing 31\% of all global deaths. An estimated 7.4 million deaths were due to coronary heart disease and 6.7 million were due to stroke. Over three quarters of CVD deaths take place in low- and middle-income countries. Most cardiovascular diseases can be prevented by addressing behavioural risk factors such as tobacco use, unhealthy diet and obesity, physical inactivity and harmful use of alcohol. Cardiovascular disease is caused by disorders of the heart and blood vessels, and includes coronary heart disease (heart attacks), raised blood pressure (hypertension), and heart failure (WHO, 2017b).

\section{Hepatitis}

Hepatitis disease is from the most dangerous disease and cause of death in the world specially Hepatitis C. It is a contagious liver disease that can range in severity from a mild illness lasting a few weeks to a serious, lifelong illness. The hepatitis $C$ virus is usually spread when blood from an infected person enters the body of a susceptible person. Every year, 3-4 million people are infected with the hepatitis $C$ virus. About 150 million people are chronically infected and are at risk of developing liver cirrhosis and/or liver cancer. More than 350000 people die from hepatitis correlated liver diseases every year. There are 6 genotypes of hepatitis $C$ and they may respond differently to treatment (WHO, 2017c).

\section{Cancer}

Cancer figures among the leading causes of morbidity and mortality worldwide, with approximately 14 million new cases and 8.2 million cancer related deaths in 2012. The number of new cases is expected to rise by about $70 \%$ over the next 2 decades. Among men, the 5 most common sites of cancer diagnosed in 2012 were lung, prostate, colorectum, stomach, and liver cancer. Among women the 5 most common sites diagnosed were breast, colorectum, lung, cervix, and stomach cancer. It is expected that annual cancer cases will rise from 14 million in 2012 to 22 within the next 2 decades.

Cancer is a generic term for a large group of diseases that can affect any part of the body. One defining feature of cancer is the rapid creation of abnormal cells that grow beyond their usual boundaries, and which can then invade adjoining parts of the body and spread to other organs, the latter process is referred to as metastasizing which is the major cause of death from cancer (WHO, 2017a).

\section{Machine learning techniques (MLTs)}

Machine learning is to train the system over a large databases, where the applied MLT can be used to generate extraction patterns or build a model and use the generated patterns or model to make predictions in the future for unknown cases. The data set used to learn the model is known as the training data set. The records making up the training set are referred to as training samples and are randomly selected from the sample population. The model is built collectively from the training data set. Since the value or class label of each training sample is provided, this step is known as supervised learning (Han et al., 2006).

The data set used to measure the quality of the model is known as the test data set. Test data set is used to estimate the predictive accuracy of the model. Test samples are randomly selected and are independent of the training samples. The accuracy of a model on a given test set is the percentage of test samples that are correctly predicted by the model. (Han et al., 2006). If the accuracy of the model is considered acceptable, the model can be used to classify or predict future data records or objects for which the class label or value is unknown. Fig. 1 shows the different steps of learning.

The different MLTs can be compared and evaluated by the following criteria:

- Speed: The computation costs involved in generating and using the model.

- Scalability: The ability to construct the model efficiently given large amount of data.

- Interpretability: The level of understanding that is provided by the model.

- Predictive accuracy: The ability of the model to correctly predict the class label or value of new or previously unseen 




Fig. 1. The different steps of learning.

data (Han et al., 2006), it can be calculated using the following formula.

Accuracy $=\frac{\mathrm{TP}+\mathrm{TN}}{\mathrm{TP}+\mathrm{TN}+\mathrm{FP}+\mathrm{FN}}$

Where (TP) is true positives, (FP) is false positives, (TN) is true negatives, and (FN) is false negatives. Other performance measures can be used to evaluate the ability of the model to correctly predict the new data which are sensitivity, specificity, positive predictive value, and negative predictive value, and Area Under Curve (AUC), they are defined as follow:

Sensitivity $=\frac{\mathrm{Tp}}{\mathrm{TP}+\mathrm{FN}}$
Specificity $=\frac{\mathrm{TN}}{\mathrm{TN}+\mathrm{FP}}$

Positive Predictive value $=\frac{\mathrm{TP}}{\mathrm{TP}+\mathrm{FP}}$

Negative Predictive value $=\frac{\mathrm{TN}}{\mathrm{TN}+\mathrm{FN}}$

AUC is a common metric that represents a way to choose optimal models and ignore suboptimal ones. It is the area under the Receiver Operating Characteristic curve (ROC), which is a curve of the true positive rate versus the false positive rate. The AUC takes a value between 0 and 1 . A good diagnostic test is obtained when the AUC is close to one.

This research has tackled the application of MLTs in the management of diseases. In the next subsections an overview of widely used MLTs in the applications of management of the adopted diseases is presented.

\section{K-nearest neighbours (K-NN)}

K-nearest neighbours is a simple algorithm that stores all available cases and classifies new cases based on a similarity measure. It is called memory-based classification as the training examples need to be in the memory at run-time. To classify an unlabelled object, the distance of this object to the labelled objects is computed, its k-nearest neighbours are identified, and the class that appears most among the neighbours is assigned to the element to be classified. Different formulas can be used to calculate the distance between a test sample and the training samples; the Euclidean distance is the most common formula.
Thus, building the model is cheap, but classifying unknown objects is relatively expensive since it requires the computation of the k-nearest neighbours of the object to be classified. This requires computing the distance of the unlabelled object to all the objects in the labelled set, which can be expensive particularly for large training sets.

Several key issues affect the performance of K-NN, such as the value of $\mathrm{k}$. If $\mathrm{k}$ is too small, then the result will be sensitive to noise points. If $\mathrm{k}$ is too large, then the boundaries between classes will be less distinct (i.e. the neighbourhood may include too many points from other classes). In the case of a binary classification, it is better to set odd value for $\mathrm{k}$, it avoids the equal vote. The accuracy of the kNN can also be affected by the irrelevant features, or if the feature scales are not consistent with their importance, distance will be dominated by large scaled features (Bremner et al., 2005; Medjahed et al., 2013; Wu et al., 2008).

\section{Artificial neural network (ANN)}

Artificial neural network is a powerful tool for modelling data, where it is able to capture and represent complex input/output relationships. The purpose of the neural network is to create a model that correctly maps the input to the output using data so that the model can be used to produce the output when the desired output is unknown. ANNs are built from multi-layer of nodes linking each other. It includes an "input" layer, one or more "hidden" layers, and the "output" layer to represent the result. The number of neurons in a layer and the number of layers depends strongly on the complexity of the studied system. The neurons in the input layer receive the data and transfer them to neurons in the first hidden layer through the weighted links. The data are mathematically processed and the result is transferred to the neurons in the next layer. The neurons in the last layer provide the network's output. The computations of ANN are very complex. The lack of explanatory is a limitation for ANNs it is like a "black box". So, it is difficult to interpret the approaches and decisions of each node in the networks and also the validation of the networks is not any easy task (Amato et al., 2013; Han et al., 2006).

\section{Associative classification}

Associative Classification (AC) is a classification approach which aims to discover a small set of rules in the database, called class association rules (CARs), to form a classifier. Building a prediction model using AC consists of two phases: 1) generate CARs and 
2) building a classifier from the generated CARs (Ma and Liu, 1998; Thabtah and Cowling, 2007).

CARs generation. CARs generation is done by focusing on a special subset of association rules whose right-hand-side is restricted to the classification class attribute. AC algorithms discover frequent rule items (attributes values that occur with a class label above the user specified support threshold). From the frequent rule items CARs can be generated. The generated CARs are of the form:

condset $\rightarrow$ class $\leftrightarrow$ (feature, value) ${ }_{\mathrm{k}} \rightarrow$ class (support, confidence)

Where "condset" is a set of items; each item is (feature, value) pair. " $\leftrightarrow$ " refers to similar 2 forms, $(\mathrm{k}=1,2,$.$) is the number of items in the$ left hand side of the rule.

Building classifier from the generated CARs. To build classifier from generated CARs most AC algorithms sort the discovered rules according to their confidence, support values, number of items in the rules and prior rule and then apply pruning heuristics to discard redundant and useless rules. A popular pruning method in AC mining is called database coverage.

However, AC algorithm suffers from repeated database scanning, huge number of candidates' generation, high computation during candidacy generation, high number of generated redundant rules (Ma and Liu, 1998; Thabtah and Cowling, 2007).

\section{Decision tree}

Decision tree is a flow-chart-like structure, where each internal node of the tree represents a test on one of the attributes, the branches from the node label the possible outcomes from the test node, and tree leaves represent classes. The topmost node in a tree is the root node. In order to classify an unknown sample, the attribute values of the sample are tested against the decision tree. A path is traced from the root to a leaf node that holds the class prediction for the sample. Overlapping in the classes and over fitting of the data are from the drawbacks of decision trees. Also, the decision trees are hard to be optimized (Bramer, 2007).

\section{Materials and methods}

\section{Search criteria}

The primary aim of this review is to find the answer for the following research questions:
- Which of the adopted MLTs is applied to manage the adopted diseases?

- What are the evaluation criteria used for the assessment of MLTs in the management of diseases?

- What are the data sets used for applying MLTs in the management of adopted diseases?

- What are the problems solved using MLTs applications in the management of diseases?

The most relevant articles were investigated from Science Direct (Elsevier) scientific database (http://www.sciencedirect. com), but only studies that satisfied the following inclusion criteria are included: (1) cancers, hepatitis and heart diseases are the only diseases considered; the considered disease should be the primary disease of the article (2) at least one of the adopted MLT is used to manage the disease; (3) the most common prediction performance measures of the applied MLTs are reported (4) all researches must be a full complete paper; (5) work published in between 2011 to July 2017 only are considered. Some other relevant researches are excluded such as books, surveys, and non-English researches. Totally, 200 studies were investigated; articles irrelevant to the inclusion search criteria are excluded. Only 56 studies (28\%) are fitted well with the search criteria and thus included while the remaining 144 studies are excluded. Fig. 2 shows a flow diagram which summarizes the selection of the retrieved researches. It should be noted that many articles include more than one MLT, and they were all counted when constructing the corresponding diagrams.

\section{Data extraction}

The data extracted from the selected articles which satisfy the inclusion criteria is presented in Tables 1-3 which present the search results for heart disease (HD), hepatitis, and cancer respectively. These tables summarize existing literature articles which were collected in this survey that were used to manage the adopted diseases using MLTs namely K-NN, DT, ANN, and AC. The first column refers to the investigated research; the second column is the used MLT to manage the disease; the third column refers to the tackled disease in the article; the fourth column refers to the scope or the problem which tried to be solved in the article; the fifth column is the achieved prediction performance in the literature which are: accuracy (Acc), Sensitivity (Sn), Specificity (Sp), and Area Under the Curve (AUC); and finally the last

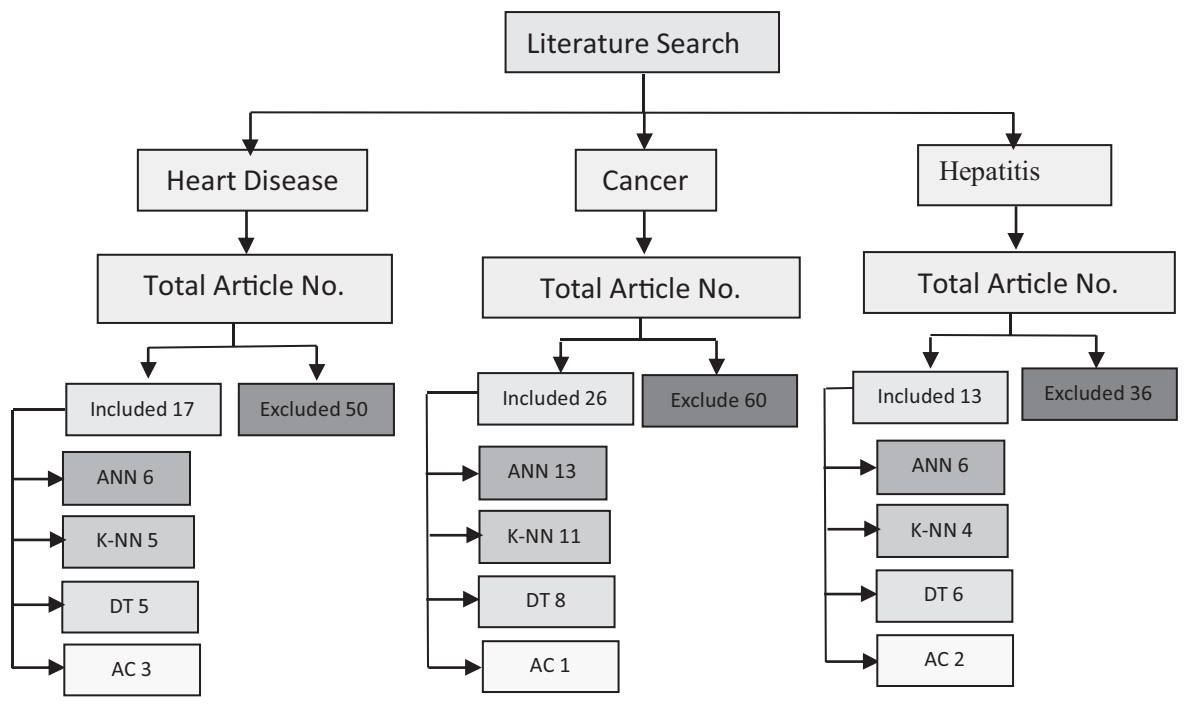

Fig. 2. Flow diagram which summarizes the selection of the retrieved researches. 
Table 1

Summary of researches which used different MLT to manage Heart Diseases.

\begin{tabular}{|c|c|c|c|c|c|}
\hline References & MLT & Disease & Scope & $\begin{array}{l}\text { Prediction } \\
\text { performance }\end{array}$ & Dataset \\
\hline Acharya et al., 2017 & K-NN & $\begin{array}{l}\text { Coronary Artery } \\
\text { Disease (CAD) }\end{array}$ & Discriminate normal and CAD ECG classes & DT & $\begin{array}{l}\text { St. Petersburg Institute of } \\
\text { Cardiological Technics } 12 \text {-lead } \\
\text { Arrhythmia database and } \\
\text { fantasia open access database }\end{array}$ \\
\hline & DT & & & $\begin{array}{l}\text { Acc }=98.99 \% \\
\text { Sp }=99.39 \% \\
\text { Sn }=97.75 \%\end{array}$ & \\
\hline Tayefi et al., 2017 & DT & $\begin{array}{l}\text { Coronary heart } \\
\text { disease (CHD) }\end{array}$ & Identify the presence of CHD & $\begin{array}{l}\text { Acc }=94 \% \\
\text { Sp }=87 \% \\
\text { Sn }=96 \%\end{array}$ & $\begin{array}{l}\text { Private dataset of } 2346 \\
\text { individuals }\end{array}$ \\
\hline Samuel et al., 2017 & ANN & Heart failure & Predict heart failure risks & $\begin{array}{l}\text { Acc }=91.1 \% \\
S p=84.0 \% \\
S n=100 \%\end{array}$ & $\begin{array}{l}\text { UCI Machine Learning } \\
\text { Repository } \\
\text { http://archive.ics.uci.edu/ml/ } \\
\text { datasets/Heart+Disease }\end{array}$ \\
\hline Elmasri et al., 2016 & K-NN & $\begin{array}{l}\text { Abdominal aortic } \\
\text { calcification }\end{array}$ & $\begin{array}{l}\text { Detect \&quantify the severity of abdominal aortic } \\
\text { calcification }\end{array}$ & $\begin{array}{l}\mathrm{Sn}=100 \% \\
\mathrm{Acc}=95.2 \%\end{array}$ & Private data \\
\hline $\begin{array}{l}\text { Lubaib and } \\
\text { Muneer, } 2016\end{array}$ & $\mathrm{~K}-\mathrm{NN}$ & HD & Diagnosis of heart disease & Acc $=99.80 \%$ & $\begin{array}{l}\text { Michigan university website } \\
\text { Phonocardiogram (PCG) signals }\end{array}$ \\
\hline $\begin{array}{l}\text { Ruiz-Fernández } \\
\text { et al., } 2016\end{array}$ & ANN & Congenital heart & $\begin{array}{l}\text { Decision support when classifying the risk of } \\
\text { congenital heart surgery }\end{array}$ & ANN & $\begin{array}{l}\text { Children heart disease database } \\
\text { of } 2432 \text { cases gathered from } \\
\text { Cardiovascular Foundation of } \\
\text { Colombia }\end{array}$ \\
\hline & DT & & & Acc $=99.87 \%$ & \\
\hline $\begin{array}{l}\text { Hosseini et al., } \\
2015\end{array}$ & K-NN & Atherosclerosis & $\begin{array}{l}\text { Identify non-invasively patients at greater risk of } \\
\text { coronary stenosis }\end{array}$ & $\begin{array}{l}\text { Acc }=81.5 \% \\
S p=80.9 \% \\
S n=82.0 \%\end{array}$ & Private data \\
\hline El-Bialy et al., 2015 & DT & CHD & Diagnosis of CHD & $\mathrm{Acc}=78.54 \%$ & $\begin{array}{l}\text { UCI Machine Learning } \\
\text { Repository }\end{array}$ \\
\hline Thomas et al., 2015 & ANN & Cardiac arrhythmias & Classify cardiac arrhythmias & $\mathrm{Sn}=94.64 \%$ & ECG Arrhythmia database \\
\hline Rashid et al., 2014 & $\begin{array}{l}\text { Association Rules } \\
\text { mining }\end{array}$ & HD & $\begin{array}{l}\text { Predict the correlations among primary disease } \\
\text { and secondary disease }\end{array}$ & & Computer generated \\
\hline Jabbar et al., 2013 & $\mathrm{AC}$ & $\mathrm{HD}$ & Explore risk factors associated with heart disease & Acc $=84 \%$ & Private data \\
\hline Nahar et al., 2013 & $\begin{array}{l}\text { Association Rules } \\
\text { mining }\end{array}$ & HD & Detect sick and healthy conditions & Acc $=99.38 \%$ & $\begin{array}{l}\text { UCI heart disease dataset } \\
\text { http://archive.ics.uci.edu/ml/ } \\
\text { machine-learning-databases/ } \\
\text { heart-disease/ }\end{array}$ \\
\hline $\begin{array}{l}\text { Rajeswari et al., } \\
2012\end{array}$ & ANN & $\begin{array}{l}\text { Ischemic Heart } \\
\text { Disease (IHD) }\end{array}$ & Diagnosis of IHD & Acc $=89.4 \%$ & $\begin{array}{l}\text { Private data } \\
712 \text { patients }\end{array}$ \\
\hline $\begin{array}{l}\text { Shouman et al., } \\
2012\end{array}$ & $\mathrm{~K}-\mathrm{NN}$ & HD & Predict patients at high risk of having HD disease & $\begin{array}{l}\text { Acc }=97.4 \% \\
\text { Sp }=99 \% \\
\text { Sn }=93.8 \%\end{array}$ & $\begin{array}{l}\text { UCI Machine Learning } \\
\text { Repository } \\
\text { http://archive.ics.uci.edu/ml/ } \\
\text { datasets/Heart+Disease }\end{array}$ \\
\hline $\begin{array}{r}\text { Karabulut and } \\
\text { İbrikçi, } 2012\end{array}$ & ANN & HD & Diagnosis of coronary artery disease & $\begin{array}{l}\text { Acc }=91.2 \% \\
\text { Sp }=86.7 \% \\
\text { Sn }=95.6 \% \\
\text { AUC }=0.915\end{array}$ & $\begin{array}{l}\text { http://archive.ics.uci.edu/ml/ } \\
\text { datasets/Heart+Disease }\end{array}$ \\
\hline Atkov et al., 2012 & ANN & HD & Diagnosis of coronary artery disease & Acc $=94 \%$ & $\begin{array}{l}\text { Private data } \\
487 \text { patients }\end{array}$ \\
\hline $\begin{array}{l}\text { Shouman et al., } \\
2011\end{array}$ & DT & HD & Predict heart disease patient & $\begin{array}{l}\text { Acc }=84.10 \% \\
\text { Sp }=85.2 \% \\
\text { Sn }=77.9 \%\end{array}$ & $\begin{array}{l}\text { http://archive.ics.uci.edu/ml/ } \\
\text { datasets/Heart+Disease }\end{array}$ \\
\hline
\end{tabular}

column refers to the used dataset and number of used cases if available.

\section{Results analysis of extracted data}

This section presents the analysis of the results shown in Tables 1-3. The collected articles covered the period from 2011 to July 2017. Fig. 3 shows the rate of collected publications for each disease in this time period according to the specified criteria. It is clear that the number of publications is varying slowly over time and it still may be increased in the next time stage. The percentage of publications in cancer is more than the other 2 diseases. The percentage of publications in hepatitis is the less, that is may be due to the countries that suffer from hepatitis are limited. It is also noted from Table 3 that the percentage of publications in breast cancer is more than the other types of cancers publications. The obtained data have been presented using pie chart to find the most prominent diseases in the collected papers in general as shown in Fig. 4. 
Table 2

Summary of researches which used different MLT to manage hepatitis diseases.

\begin{tabular}{|c|c|c|c|c|c|}
\hline References & MLT & Disease & Scope & Prediction performance & Dataset \\
\hline Chen et al., 2017 & $\begin{array}{l}\text { DT } \\
\text { K-NN }\end{array}$ & Hepatitis B & $\begin{array}{l}\text { Evaluate the stage of hepatic } \\
\text { fibrosis }\end{array}$ & $\begin{array}{l}\text { DT } \\
\text { Acc }=82.87 \% \\
\text { Sp }=64.99 \% \\
\text { Sn }=89.41 \%\end{array}$ & $\begin{array}{l}\text { Real-time tissue elastography } \\
\text { private data }\end{array}$ \\
\hline Rau et al., 2016 & ANN & Liver cancer & Predict liver cancer & $\begin{array}{l}\text { Sp }=75.5 \% \\
\text { Sn }=75.7 \% \\
\text { AUC }=0.873\end{array}$ & $\begin{array}{l}\text { National Health Insurance } \\
\text { Research Database of Taiwan }\end{array}$ \\
\hline Hayashi and Fukunaga, 2016 & Association Rules & Hepatitis & $\begin{array}{l}\text { Quantify the associations } \\
\text { between the presence \& } \\
\text { severity of ascites and serum } \\
\text { biomarkers with the risk of } \\
\text { developing hepatitis }\end{array}$ & $\mathrm{Acc}=83.24 \%$ & $\begin{array}{l}\text { UCI machine learning } \\
\text { repository }\end{array}$ \\
\hline Femina, 2015 & K-NN & Hepatitis & Diagnosis of hepatitis' diseases & $\begin{array}{l}\text { AUC }=0.67 \\
\text { Acc }=84.52 \%\end{array}$ & $\begin{array}{l}\text { BUPA and Hepatitis datasets } \\
\text { UCI Machine Learning } \\
\text { Repository }\end{array}$ \\
\hline El Houby, 2014 & $\begin{array}{l}\text { AC } \\
\text { DT } \\
\text { ANN }\end{array}$ & Hepatitis C & $\begin{array}{l}\text { Predict patients' response to } \\
\text { Hepatitis } C \text { virus treatment }\end{array}$ & $\begin{array}{l}\underline{\text { AC }} \\
\text { Acc }=92 \% \\
\text { Sp }=100 \% \\
\text { Sn }=81.8 \% \\
\text { AUC }=0.909\end{array}$ & Private data \\
\hline Kayaaltı et al., 2014 & K-NN & Chronic hepatitis & Determine liver fibrosis stage & $\mathrm{Acc}=95 \%$ & $\begin{array}{l}\text { Private data } \\
\text { CT images }\end{array}$ \\
\hline Yau et al., 2014 & DT & Hepatitis B & $\begin{array}{l}\text { Prognostic classification with } \\
\text { treatment guidance for Asian } \\
\text { patients with hepatocellular } \\
\text { carcinoma }\end{array}$ & AUC $=0.84$ & Private data \\
\hline Kaya and Uyar, 2013 & ANN & Hepatitis & $\begin{array}{l}\text { Identify whether patients } \\
\text { suffering hepatitis are } \\
\text { predicted to be alive or not }\end{array}$ & Acc $=100 \%$ & $\begin{array}{l}3856 \text { patients } \\
\text { UCI Machine Learning } \\
\text { Repository }\end{array}$ \\
\hline & & & & $\begin{array}{l}S p=100 \% \\
S n=100 \%\end{array}$ & \\
\hline Kawamura et al., 2012 & DT & Hepatitis C & $\begin{array}{l}\text { Predict patients' response to } \\
\text { hepatitis C virus treatment }\end{array}$ & Acc $=93 \%$ & Private data \\
\hline Hashem et al., 2012 & $\begin{array}{l}\text { ANN } \\
\text { DT } \\
\text { K-NN }\end{array}$ & Hepatitis C & $\begin{array}{l}\text { Predict fibrosis or cirrhosis in } \\
\text { patients with hepatitis } C \text { virus }\end{array}$ & ANN & Private data \\
\hline & & & & $\begin{array}{l}\mathrm{Sp}=92.1 \% \\
\mathrm{Sn}=84.8 \%\end{array}$ & 355 patients \\
\hline Kurosaki et al., 2011 & DT & Hepatitis C & $\begin{array}{l}\text { Pre-treatment prediction of } \\
\text { response using host and viral } \\
\text { factors }\end{array}$ & $\mathrm{Sp}=70 \%$ & Private data \\
\hline & & & & $\begin{array}{l}\mathrm{Sn}=78 \% \\
\mathrm{AUC}=0.782\end{array}$ & 496 patients \\
\hline Jilani et al., 2011 & ANN & Hepatitis C & Diagnosis of hepatitis $C$ virus & Acc $=99.1 \%$ & $\begin{array}{l}\text { UCI Machine Learning } \\
\text { Repository }\end{array}$ \\
\hline Resino et al., 2011 & ANN & Hepatitis C & Predict fibrosis & $\begin{array}{l}\mathrm{Sp}=94.9 \% \\
\mathrm{Sn}=53.8 \% \\
\mathrm{AUC}=0.868\end{array}$ & Private data \\
\hline
\end{tabular}

The numbers of the used MLTs for each disease in the collected papers are shown in Fig. 5. The obtained MLTs data have been presented using pie chart to find the most prominent technique used in management of diseases in general as declared in Fig. 6. It is noticed that ANN is the most used classification technique for management of diseases, and then K-NN, followed by DT comes afterwards. And finally it is clear that AC has been explored but has not been widely adopted.

In Tables 1-3 some studies use more than one MLT to find the technique that achieve the best result, in this case all of them are mentioned and only the best achieved results are recorded in the tables. In the investigated literature, it is found that the most common problem or scope is "classify or diagnosis of the disease".

In data extraction, the used datasets in each article are collected as well as the number patients if stated in the article. Some public databases are widely used in literature such as (UCI Machine Learning Repository, 2017) which is the site for University of
California, Irvine Learning Repository (California). It contains databases for the 3 adopted diseases of this review. Many other articles use private data which had been collected from local hospitals, Universities or research centers. Also the most used digital images databases in the articles are Digital Database for Screening Mammography DDSM (Heath et al., 2000), MIAS (Suckling et al., 2015) and IRMA (Oliveira et al., 2008). The links of other databases are provided in the tables if it is mentioned in the article reference.

\section{Discussion and conclusion}

This research presented the general philosophy for the use of MLTs in management of diseases through the adopted diseases and techniques. The state-of-the-art of the applications of ANN, K-NN, DT, and AC on different data sets for adopted diseases was illustrated. MLTs use various data, ranging from clinical features to 
Table 3

Summary of researches which used different MLT to manage cancers diseases.

\begin{tabular}{|c|c|c|c|c|c|}
\hline References & MLT & Disease & Problem & Prediction performance & Dataset \\
\hline \multirow[t]{3}{*}{ Acharya et al., 2016} & DT & Thyroid cancer & $\begin{array}{l}\text { Classify as benign or malignant } \\
\text { thyroid nodules }\end{array}$ & $\underline{\text { DT }}$ & $\begin{array}{l}242 \text { thyroid high resolution } \\
\text { ultrasound images }\end{array}$ \\
\hline & K-NN & & & Acc $=94.3 \%$ & \\
\hline & ANN & & & AUC $=0.9429$ & \\
\hline \multirow[t]{3}{*}{ Guo et al., 2017} & DT & Breast cancer & $\begin{array}{l}\text { Predict models for breast } \\
\text { cancer recurrence }\end{array}$ & $\mathrm{Acc}=70 \%$ & Private data \\
\hline & & & & $S p=92 \%$ & 574 patients \\
\hline & & & & $\mathrm{Sn}=40 \%$ & \\
\hline \multirow{3}{*}{ Gardezi et al., 2017} & K-NN & Breast cancer & Classify as normal or abnormal & Acc $=92.81 \%$ & IRMA \\
\hline & & & & $\mathrm{Sn}=92.85 \%$ & MIAS \\
\hline & & & & AUC $=0.9713$ & \\
\hline \multirow[t]{3}{*}{ Mohammed et al., 2017} & ANN & $\begin{array}{l}\text { Nasopharyngeal } \\
\text { Carcinoma }\end{array}$ & $\begin{array}{l}\text { Identify nasopharyngeal } \\
\text { carcinoma }\end{array}$ & Acc $=91.1 \%$ & Private data \\
\hline & & & & $\mathrm{Sp}=90.01 \%$ & 149 microscope images \\
\hline & & & & $S n=93.24 \%$ & \\
\hline \multirow[t]{2}{*}{ Iraji, 2017} & ANN & Lung cancer & $\begin{array}{l}\text { Predict } 1 \text {-year the post- } \\
\text { operative survival expectancy }\end{array}$ & $S p=81.57 \%$ & Private data \\
\hline & & & & $S n=90.05 \%$ & 470 sample \\
\hline \multirow[t]{3}{*}{ Acharya et al., 2016} & DT & Thyroid cancer & $\begin{array}{l}\text { Classification of benign and } \\
\text { malignant thyroid nodules }\end{array}$ & $\underline{\text { DT }}$ & $\begin{array}{l}242 \text { thyroid high resolution } \\
\text { ultrasound images }\end{array}$ \\
\hline & K-NN & & & Acc $=94.3 \%$ & \\
\hline & ANN & & & & \\
\hline Kumar et al., 2016 & $\mathrm{~K}-\mathrm{NN}$ & Leukemia & Classify microarray data & $\mathrm{Acc}=92.52 \%$ & $\begin{array}{l}\text { National Center of } \\
\text { Biotechnology Information } \\
\text { http://www.ncbi.nlm.nih.gov/ } \\
\text { gds/ }\end{array}$ \\
\hline \multirow[t]{2}{*}{ Sayed et al., 2016} & K-NN & Breast cancer & $\begin{array}{l}\text { Classify breast tumours } \\
\text { screened into benign \& } \\
\text { malignant }\end{array}$ & Acc $=98.92 \%$ & Private data \\
\hline & & & & & MRI \\
\hline Khalilabad et al., 2016 & DT & Breast cancer & Detect of breast cancer type & Acc $=95.23 \%$ & $\begin{array}{l}\text { Stanford Microarray Database } \\
\text { http://smd.stanford.edu/ }\end{array}$ \\
\hline \multirow[t]{3}{*}{ Peng et al., 2016} & ANN & Breast cancer & $\begin{array}{l}\text { Online classification as normal } \\
\text { benign/malignant tumour }\end{array}$ & Acc $=96 \%$ & MIAS \\
\hline & & & & $S p=89.3 \%$ & BancoWeb \\
\hline & & & & $\mathrm{Sn}=98.6 \%$ & \\
\hline \multirow[t]{3}{*}{ Sethi and Saini, 2016} & ANN & Abdomen diseases & Classify abdomen diseases & Acc $=95.1 \%$ & Private data \\
\hline & & & & $\mathrm{Sp}=98 \%$ & $120 \mathrm{CT}$ images \\
\hline & & & & $\mathrm{Sn}=95 \%$ & \\
\hline \multirow[t]{3}{*}{ O’Shea et al., 2016} & ANN & Lung cancer & Classify lung cancer & $\mathrm{Sp}=100 \%$ & Private data \\
\hline & & & & $\mathrm{Sn}=80 \%$ & \\
\hline & & & & $\mathrm{AUC}=1$ & \\
\hline \multirow[t]{2}{*}{ Hayashi and Nakano, 2015} & DT & Breast cancer & Diagnosis of breast cancer & Acc $=95.80 \%$ & $\mathrm{UCI}(\mathrm{WBCD})$ \\
\hline & & & & AUC $=0.959$ & http://archive/ics.uci/edu/m/ \\
\hline \multirow[t]{3}{*}{ Chen et al., 2015} & DT & $\begin{array}{l}\text { Nasopharyngeal } \\
\text { carcinoma }\end{array}$ & $\begin{array}{l}\text { Classify between tumour and } \\
\text { normal cell lines }\end{array}$ & Acc $=98.5 \%$ & Private data \\
\hline & & & & $\mathrm{Sp}=96.9 \%$ & \\
\hline & & & & Sn $=99.0 \%$ & \\
\hline \multirow[t]{4}{*}{ Onan, 2015} & K-NN & Breast cancer & Diagnosis for breast cancer & Acc $=99.72 \%$ & $\begin{array}{l}\text { UCI Machine Learning } \\
\text { Repository }\end{array}$ \\
\hline & & & & $\mathrm{Sp}=99.47 \%$ & WBCD \\
\hline & & & & Sn $=100 \%$ & \\
\hline & & & & $\mathrm{AUC}=1$ & \\
\hline \multirow[t]{3}{*}{ Bethapudi et al., 2015} & DT & Breast cancer & $\begin{array}{l}\text { Predict benign and malignant } \\
\text { breast cancer cases }\end{array}$ & Acc $=81.4 \%$ & (BI-RADS) UCI \\
\hline & & & & $S p=77.2 \%$ & $\begin{array}{l}\text { Archive.Ics.Uci.Edu/Ml/ } \\
\text { Machine-Learning-databases/ } \\
\text { mammographic-masses/ } \\
\text { mammographic_masses.data }\end{array}$ \\
\hline & & & & $S n=85.06 \%$ & \\
\hline \multirow[t]{4}{*}{ Mohamed et al., 2014} & ANN & Breast cancer & $\begin{array}{l}\text { Classify between normal and } \\
\text { micro calcifications and then } \\
\text { between benign \& malignant }\end{array}$ & ANN & MIAS \\
\hline & K-NN & & & $A c c=71 \%$ & \\
\hline & & & & $\mathrm{Sp}=77 \%$ & \\
\hline & & & & $\mathrm{Sn}=66 \%$ & \\
\hline Medjahed et al., 2013 & K-NN & Breast cancer & $\begin{array}{l}\text { Diagnosis and classification of } \\
\text { breast cancer }\end{array}$ & Acc $=98.7 \%$ & WBCD \\
\hline Mohanty et al., 2013 & AC & Breast cancer & $\begin{array}{l}\text { Different between normal and } \\
\text { cancer breast tissue }\end{array}$ & $S p=96.88 \%$ & $\begin{array}{l}\text { Digital database for screening } \\
\text { mammography (DDSM) }\end{array}$ \\
\hline & & & & $S n=96.5 \%$ & $\begin{array}{l}\text { http://marathon.csee.usf.edu/ } \\
\text { Mammography/Database.html }\end{array}$ \\
\hline Mahmoud et al., 2013 & K-NN & $\begin{array}{l}\text { Small, Round Blue } \\
\text { Cell Tumours (SRBCT) }\end{array}$ & $\begin{array}{l}\text { Find a small set of highest } \\
\text { informative genes to classify } \\
\text { cancer }\end{array}$ & Acc $=00 \%$ using 26 genes & $\begin{array}{l}\text { http://research.nhgri.nih.gov/ } \\
\text { microarray/Supplement/ }\end{array}$ \\
\hline
\end{tabular}




\begin{tabular}{|c|c|c|c|c|c|}
\hline References & MLT & Disease & Problem & Prediction performance & Dataset \\
\hline & & Leukemia & & Acc $=97.06 \%$ using 10 genes & $\begin{array}{l}\text { http://www.broadinstitute. } \\
\text { org/cgibin/cancer/publications/ } \\
\text { pub_paper.cgi?mode\%20=\% } \\
\text { 20view\&paper_id=43 }\end{array}$ \\
\hline \multirow[t]{2}{*}{ Kowal et al., 2013} & K-NN & Breast cancer & Classify as benign/malignant & All classifiers & Private data \\
\hline & DT & & & Acc $=96-100 \%$ & 500 images \\
\hline \multirow[t]{3}{*}{ Săftoiu et al., 2012} & ANN & Pancreatic cancer & Diagnosis of breast cancer & $\mathrm{Acc}=91.14 \%$ & $\begin{array}{l}\text { Private ultrasound (EUS) } \\
\text { elastography }\end{array}$ \\
\hline & & & & $\mathrm{Sp}=82.94 \%$ & 258 patients \\
\hline & & & & $S n=87.59 \%$ & \\
\hline \multirow[t]{2}{*}{ Flores-Fernández et al., 2012} & ANN & Lung cancer & Classify lung cancer patients & $S p=80 \%$ & Private data \\
\hline & & & & $\begin{array}{l}\mathrm{Sn}=95.9 \% \\
\mathrm{AUC}=0.933\end{array}$ & \\
\hline \multirow[t]{3}{*}{ Thakur et al., 2011} & ANN & Ovarian cancer & Diagnosis of ovarian cancer & $A c c=99.16 \%$ & $\begin{array}{l}\text { FDA-NCI Clinical Proteomics } \\
\text { Program Databank website }\end{array}$ \\
\hline & & & & $S p=96 \%$ & $\begin{array}{l}\text { http://home.ccr.cancer.gov/ } \\
\text { ncifdaproteomics/ppatterns. } \\
\text { asp }\end{array}$ \\
\hline & & & & Sn $=98 \%$ & \\
\hline Wu et al., 2011 & ANN & Lung cancer & Diagnosis of lung cancer & $A c c=92.8 \%$ & Private data \\
\hline & & & & $S p=100 \%$ & \\
\hline & & & & $\mathrm{Sn}=98 \%$ & \\
\hline \multirow[t]{4}{*}{ Ruiz et al., 2011} & ANN & Skin cancer & Diagnosis using image & ANN & Private image \\
\hline & $\mathrm{K}-\mathrm{NN}$ & Melanoma & & $\overline{\mathrm{AcC}}=86.73 \%$ & 98 dermoscopic images \\
\hline & & & & $S p=95.74 \%$ & \\
\hline & & & & $\mathrm{Sn}=78.43 \%$ & \\
\hline \multirow[t]{6}{*}{ Acharya et al., 2011} & K-NN & Thyroid cancer & Diagnosis of malignant and & $\underline{\text { K-NN }}$ & 20 (10 benign \& 10 malignant) \\
\hline & & & benign thyroid lesions & & $\begin{array}{l}\text { 3D contrast-enhanced } \\
\text { ultrasound images. }\end{array}$ \\
\hline & ANN & & & Acc $=98.9 \%$ & \\
\hline & DT & & & $S p=99.8 \%$ & \\
\hline & & & & $\mathrm{Sn}=98 \%$ & \\
\hline & & & & AUC $=0.987$ & \\
\hline
\end{tabular}

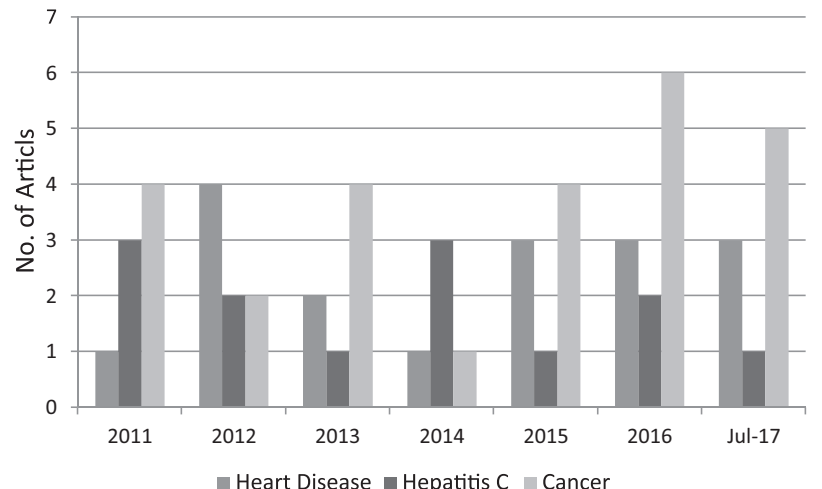

Fig. 3. Number of collected papers of the adopted disease from 2012 to July 2017 using specified criteria.

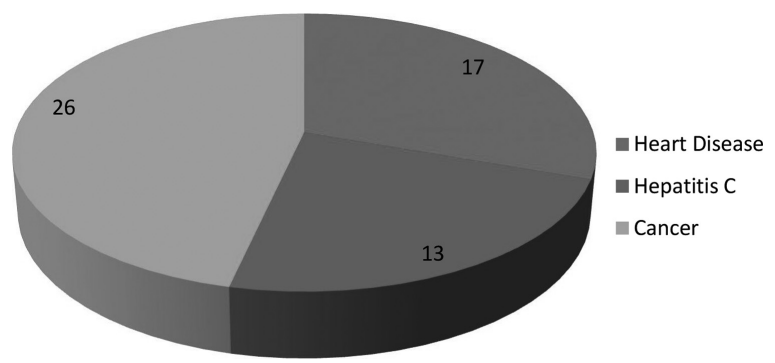

Fig. 4. The percentage of the diseases in the collected papers in the review.

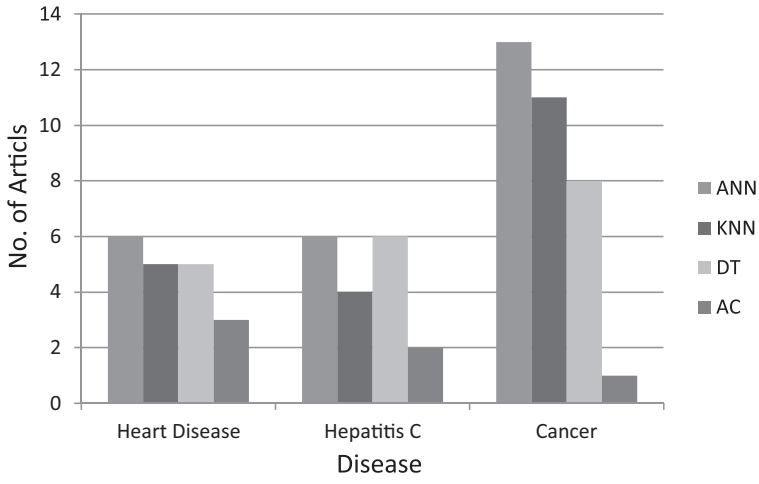

Fig. 5. The numbers of the used MLTs in the collected papers.



Fig. 6. The percentage of MLTs in general in all collected papers in this review. 
digital mammograms, and provide acceptable accuracy for different diseases.

Although predictive performance measures, speed, scalability, and interpretability are the used criteria to evaluate different MLTs, the predictive performance measures are the mostly used criteria to evaluate the applications of MLTs for management of disease. The reason for that may because the management of diseases is related to human life, so the predictive performance is more important than other criteria, also the available patient databases are always relatively small, so speed, scalability are not problematic.

The achieved accuracy for management of diseases using different techniques is differed and ranged from $70 \%$ to $100 \%$ according to the solved problem, disease, and the used technique. The highest accuracy for heart disease is $99.87 \%$ using ANN to build decision support system for classifying the risk of congenital heart surgery. The best accuracy for hepatitis disease is $100 \%$ using ANN to identify whether patients suffering hepatitis are predicted to be alive or not. And the best accuracy for cancer is $100 \%$ using K-NN to classify SRBCT cancer using 26 genes.

The highest achieved accuracy for K-NN is $100 \%$ for cancer disease to classify SRBCT cancer using 26 genes. The highest achieved accuracy for ANN is $100 \%$ for hepatitis disease to identify whether patients suffering hepatitis are predicted to be alive or not. The highest achieved accuracy for DT is $98.99 \%$ for heart disease to discriminate normal and CAD ECG classes. The highest achieved accuracy for AC is 99.38 to detect sick and healthy conditions for HD.

According to the collected data, it is difficult to comprehensively compare different techniques under different conditions. The disease, the problem, and the used data should be the same for all researches to be able to compare different applied techniques, so that a fair comparison can be conducted. Generally, among the MLTs mentioned in the literature, ANN classifier has been used extensively for management of diseases. Although AC has achieved high accuracy in the management of disease its use is limited, so it is recommended for researchers to try it in the future. Also it is recommended to investigate the usage of different MLTs in management of disease. Moreover, deep learning is a new trend that has increased interest in the recent years, it is worth studying. Developing systems for management of diseases based on deep learning is a necessity.

MLTs are proven to be suitable for management of various diseases. In addition, their use makes the disease management more reliable and therefore increases patient satisfaction. The advantages of developing MLTs for management of diseases will be reached by bringing these systems into clinics and applying them as support tools that aid physicians in diagnosis, prognosis, and treatment of diseases. The use of such systems will eliminate reading variability by physicians and radiologists, resulting in quick and more accurate diagnosis and cost and time savings for both the hospital and the patient. The feedback from the usage of MLTs in management of diseases will lead to improve their performance, and avoid their disadvantages.

\section{Conflict of interests}

The author has no conflicts of interests to declare.

\section{References}

Acharya, U.R., Faust, O., Sree, S.V., Molinari, F., Garberoglio, R., Suri, J., 2011. Costeffective and non-invasive automated benign \& malignant thyroid lesion classification in 3D contrast-enhanced ultrasound using combination of wavelets and textures: a class of ThyroScan ${ }^{\mathrm{TM}}$ algorithms. Technol. Cancer Res. Treat. 10 (4), 371-380.
Acharya, U.R., Chowriappa, P., Fujita, H., Bhat, S., Dua, S., Koh, J.E., et al., 2016. Thyroid lesion classification in 242 patient population using Gabor transform features from high resolution ultrasound images. Knowle. Based Syst. 107, 235-245.

Acharya, U.R., Sudarshan, V.K., Koh, J.E., Martis, R.J., Tan, J.H., Oh, S.L., et al., 2017 Application of higher-order spectra for the characterization of Coronary artery disease using electrocardiogram signals. Biomed. Signal Process. Control 31, 31 43.

Amato, F., López, A., Peña-Méndez, E.M., Vaňhara, P., Hampl, A., Havel, J., 2013. Artificial neural networks in medical diagnosis. J. Appl. Biomed. 11 (2), 47-58

American Medical Informatics Association, 2017. [online] [cit. 2017-11-12]. Available from: http://www.amia.org/informatics/.

Atkov, O.Y., Gorokhova, S.G., Sboev, A.G., Generozov, E.V., Muraseyeva, E.V. Moroshkina, S.Y., Cherniy, N.N., 2012. Coronary heart disease diagnosis by artificial neural networks including genetic polymorphisms and clinical parameters. J. Cardiol. 59 (2), 190-194.

Bethapudi, P., Reddy, E.S., Varma, K.V., 2015. Classification of breast cancer using Gini index based Fuzzy Supervised Learning in Quest Decision Tree Algorithm. Int. J. Comput. Appl. 111 (14), 50-57.

Bramer, M., 2007. Principles of Data Mining, vol. 180. Springer, London.

Bremner, D., Demaine, E., Erickson, J., Iacono, J., Langerman, S., Morin, P., Toussaint, G., 2005. Output-sensitive algorithms for computing nearest-neighbour decision boundaries. Discrete Comput. Geom. 33 (4), 593-604.

Brin, S., 1998. Extracting Patterns and Relations from the World Wide Web Paper Presented at the International Workshop on The World Wide Web and Databases. Springer, Berlin.

Chen, Y., Su, Y., Ou, L., Zou, C., Chen, Z., 2015. Classification of nasopharyngeal cell lines (C666 - 1 ,null ,null) via Raman spectroscopy and decision tree. Vib. Spectrosc. 80, 24-29.

Chen, Y., Luo, Y., Huang, W., Hu, D., R-, Q., S-, Z., et al., 2017. Machine-learning-based classification of real-time tissue elastography for hepatic fibrosis in patients with chronic hepatitis B. Comput. Biol. Med. 89, 18-23.

El Houby, E.M., 2014. A framework for prediction of response to HCV therapy using different data mining techniques. Adv. Bioinf. 2014, 181056. doi:http://dx.doi org/10.1155/2014/181056.

El-Bialy, R., Salamay, M.A., Karam, O.H., Khalifa, M.E., 2015. Feature analysis of coronary artery heart disease data sets. Procedia Comput. Sci. 65, 459-468.

Elmasri, K., Hicks, Y., Yang, X., Sun, X., Pettit, R., Evans, W., 2016. Automatic detection and quantification of abdominal aortic calcification in dual energy X-ray absorptiometry. Procedia Comput. Sci. 96, 1011-1021.

Femina, B.A.S., 2015. Disease diagnosis using rough set based feature selection and K-nearest neighbour classifier. Int. J. Multidiscip. Res. Dev. 2 (4), 664-668.

Flores-Fernández, J.M., Herrera-López, E.J., Sánchez-Llamas, F., Rojas-Calvillo, A. Cabrera-Galeana, P.A., Leal-Pacheco, G., et al., 2012. Development of an optimized multi-biomarker panel for the detection of lung cancer based on principal component analysis and artificial neural network modelling. Expert Syst. Appl. 39 (12), 10851-10856.

Freitas, A.A., 2003. A survey of evolutionary algorithms for data mining and knowledge discovery. In: Ghosh, A., Tsutsui, S. (Eds.), Advances in Evolutionary Computing. Natural Computing Series. Springer, Berlin, pp. 819-845.

Gardezi, S.J.S., Faye, I., Bornot, J.M.S., Kamel, N., Hussain, M., 2017. Mammogram classification using dynamic time warping. Multimedia Tools Appl. 1-22.

Guo, J., Fung, B.C., Iqbal, F., Kuppen, P.J., Tollenaar, R.A., Mesker, W.E., Lebrun, J.-J., 2017. Revealing determinant factors for early breast cancer recurrence by decision tree. Inf. Syst. Front. 1-9.

Han, J., Kamber, M., Pei, J., 2006. Data Mining: Concept and Techniques. Morgan Kaufman Publisher, San Francisco.

Hashem, A.M., Rasmy, M.E.M., Wahba, K.M., Shaker, O.G., 2012. Single stage and multistage classification models for the prediction of liver fibrosis degree in patients with chronic hepatitis C infection. Comput. Methods Programs Biomed 105 (3), 194-209.

Hayashi, Y., Fukunaga, K., 2016. Accuracy of rule extraction using a recursive-rule extraction algorithm with continuous attributes combined with a sampling selection technique for the diagnosis of liver disease. Inf. Med. Unlocked 5, 26 38.

Hayashi, Y., Nakano, S., 2015. Use of a recursive-rule eXtraction algorithm with J48graft to achieve highly accurate and concise rule extraction from a large breast cancer dataset. Inf. Med. Unlocked. 1, 9-16.

Heath, M., Bowyer, K., Kopans, D., Moore, R., Kegelmeyer, W.P., 2000. The digital database for screening mammography. Proceedings of the 5th International Workshop on Digital Mammography

Helma, C., Gottmann, E., Kramer, S., 2000. Knowledge discovery and data mining in toxicology. Stat. Methods Med. Res. 9 (4), 329-358.

Hosseini, Z.S., Zahedi, E., Attar, H.M., Fakhrzadeh, H., Parsafar, M.H., 2015 Discrimination between different degrees of coronary artery disease using time-domain features of the finger photoplethysmogram in response to reactive hyperemia. Biomed. Signal Process. Control 18, 282-292.

Huang, M., Zhu, X., Ding, S., Yu, H., Li, M., 2006. ONBRIRES: ontology-based biological relation extraction system. Proceedings of the APBC.

Iraji, M.S., 2017. Prediction of post-operative survival expectancy in thoracic lung cancer surgery with soft computing. J. Appl. Biomed. 15 (2), 151-159.

Jabbar, M.A., Deekshatulu, B.L., Chandra, P., 2013. Knowledge discovery using associative classification for heart disease prediction. Intell. Inf. 29-39.

Jilani, T.A., Yasin, H., Yasin, M.M., 2011. PCA-ANN for classification of Hepatitis-C patients. Int. J. Comput. Appl. 14 (7), 1-6 (0975-8887).

Karabulut, E.M., Ibrikçi, T., 2012. Effective diagnosis of coronary artery disease using the rotation forest ensemble method. J. Med. Syst. 36 (5), 3011-3018. 
Kawamura, Y., Takasaki, S., Mizokami, M., 2012. Using decision tree learning to predict the responsiveness of hepatitis $C$ patients to drug treatment. FEBS Open Biol. 2, 98-102.

Kaya, Y., Uyar, M., 2013. A hybrid decision support system based on rough set and extreme learning machine for diagnosis of hepatitis disease. Appl. Soft Comput. 13 (8), 3429-3438.

Kayaaltı, Ö., Aksebzeci, B.H., Karahan, İ.Ö., Deniz, K., Öztürk, M., Yılmaz, B., et al., 2014. Liver fibrosis staging using CT image texture analysis and soft computing Appl. Soft Comput. 25, 399-413.

Khalilabad, N.D., Hassanpour, H., Abbaszadegan, M.R., 2016. Fully automatic classification of breast cancer microarray images. J. Electr. Syst. Inf. Technol. 3 (2), 348-359.

Kowal, M., Filipczuk, P., Obuchowicz, A., Korbicz, J., Monczak, R., 2013. Computeraided diagnosis of breast cancer based on fine needle biopsy microscopic images. Comput. Biol. Med. 43 (10), 1563-1572.

Kumar, M., Rath, N.K., Rath, S.K., 2016. Analysis of microarray leukemia data using an efficient MapReduce-based K-nearest-neighbor classifier. J. Biomed. Inf. 60, 395-409.

Kurosaki, M., Tanaka, Y., Nishida, N., Sakamoto, N., Enomoto, N., Honda, M., et al., 2011. Pre-treatment prediction of response to pegylated-interferon plus ribavirin for chronic hepatitis C using genetic polymorphism in IL28B and viral factors. J. Hepatol. 54 (3), 439-448.

Liao, S.-C., Lee, I.-N., 2002. Appropriate medical data categorization for data mining classification techniques. Med. Inf. Internet Med. 27 (1), 59-67.

Lubaib, P., Muneer, K.A., 2016. The heart defect analysis based on PCG signals using pattern recognition techniques. Procedia Technol. 24, 1024-1031.

Ma, B.L.W.H.Y., Liu, B., 1998. Integrating classification and association rule mining Proceedings of the Fourth International Conference on Knowledge Discovery and Data Mining.

Mahmoud, A.M., Maher, B.A., El-Horbaty, E.-S.M., Salem, A.B.M., 2013. Analysis of machine learning techniques for gene selection and classification of microarray data. Proceedings of the 6th International Conference on Information Technology.

Medjahed, S.A., Saadi, T.A., Benyettou, A., 2013. Breast cancer diagnosis by using knearest neighbour with different distances and classification rules. Int. J. Comput. Appl. 62 (1) doi:http://dx.doi.org/10.5120/10041-4635.

Mohamed, H., Mabrouk, M.S., Sharawy, A., 2014. Computer aided detection system for micro calcifications in digital mammograms. Comput. Methods Programs Biomed 116 (3), 226-235.

Mohammed, M.A., Ghani, M.K.A., Hamed, R.I., Ibrahim, D.A., Abdullah, M.K., 2017 Artificial neural networks for automatic segmentation and identification of nasopharyngeal carcinoma. J. Comput. Sci. 21, 263-274.

Mohanty, A.K., Senapati, M.R., Lenka, S.K., 2013. Retracted article: an improved data mining technique for classification and detection of breast cancer from mammograms. Neural Comput. Appl. 22 (1), 303-310.

Nahar, J., Imam, T., Tickle, K.S., Chen, Y.-P.P., 2013. Association rule mining to detect factors which contribute to heart disease in males and females. Expert Syst. Appl. 40 (4), 1086-1093.

National Library of Medicine, 2017. [online] [cit. 2017-11-14]. Available from: http:// www.nlm.nih.gov/tsd/acquisitions/cdm/subjects58.html.

O’Shea, K., Cameron, S.J., Lewis, K.E., Lu, C., Mur, L.A., 2016. Metabolomic-based biomarker discovery for non-invasive lung cancer screening: a case study. Biochim. et Biophys. Acta (BBA): Gen. Subjects 1860 (11), 2682-2687.

Oliveira, J.E., Guled, M.O., Araújo, A., Ott, B., Deserno, T.M., 2008. Toward a standard reference database for computer-aided mammography. Medical Imaging. International Society for Optics and Photonics doi:http://dx.doi.org/10.1117 12.770325 .

Onan, A. 2015. A fuzzy-rough nearest neighbour classifier combined with consistency-based subset evaluation and instance selection for automated diagnosis of breast cancer. Expert Syst. Appl. 42 (20), 6844-6852.

Peng, W., Mayorga, R.V., Hussein, E.M., 2016. An automated confirmatory system for analysis of mammograms. Comput. Methods Programs Biomed. 125, 134-144.

Rajeswari, K., Vaithiyanathan, V., Neelakantan, T., 2012. Feature selection in ischemic heart disease identification using feed forward neural networks. Procedia Eng. 41, 1818-1823.
Rashid, M.A., Hoque, M.T., Sattar, A., 2014. Association Rules Mining Based Clinical Observations. arXiv preprint arXiv:1401.2571

Rau, H.-H., Hsu, C.-Y., Lin, Y.-A., Atique, S., Fuad, A., Wei, L.-M., Hsu, M.-H., 2016. Development of a web-based liver cancer prediction model for type II diabetes patients by using an artificial neural network. Comput. Methods Programs Biomed. 125, 58-65.

Resino, S., Seoane, J.A., Bellón, J.M., Dorado, J., Martin-Sanchez, F., Álvarez, E., et al., 2011. An artificial neural network improves the non-invasive diagnosis of significant fibrosis in HIV/HCV coinfected patients. J. Infect. 62 (1), 77-86.

Ruiz, D., Berenguer, V., Soriano, A., Sánchez, B., 2011. A decision support system for the diagnosis of melanoma: a comparative approach. Expert Syst. Appl. 38 (12), 15217-15223.

Ruiz-Fernández, D., Torra, A.M., Soriano-Payá, A., Marín-Alonso, O., Palencia, E.T., 2016. Aid decision algorithms to estimate the risk in congenital heart surgery. Comput. Methods Programs Biomed. 126, 118-127.

Săftoiu, A., Vilmann, P., Gorunescu, F., Janssen, J., Hocke, M., Larsen, M., et al., 2012. Efficacy of an artificial neural network-based approach to endoscopic ultrasound elastography in diagnosis of focal pancreatic masses. Clin. Gastroenterol. Hepatol. 10 (1), 84-90 e81.

Samuel, O.W., Asogbon, G.M., Sangaiah, A.K., Fang, P., Li, G., 2017. An integrated decision support system based on ANN and Fuzzy_AHP for heart failure risk prediction. Expert Syst. Appl. 68, 163-172.

Sayed, A.M., Zaghloul, E., Nassef, T.M., 2016. Automatic classification of breast tumours using features extracted from magnetic resonance images. Procedia Comput. Sci. 95, 392-398.

Sethi, G., Saini, B.S., 2016. Computer aided diagnosis system for abdomen diseases in computed tomography images. Biocybernet. Biomed. Eng. 36 (1), 42-55.

Shouman, M., Turner, T., Stocker, R., 2011. Using decision tree for diagnosing heart disease patients. Proceedings of the Ninth Australasian Data Mining Conference 121.

Shouman, M., Turner, T., Stocker, R., 2012. Applying k-nearest neighbour in diagnosing heart disease patients. Int. J. Inf. Educ. Technol. 2 (3), 220.

Suckling, J., Parker, J., Dance, D., Astley, S., Hutt, I., Boggis, C., et al., 2015. Mammographic Image Analysis Society (MIAS) Database v1.21.

Tayefi, M., Tajfard, M., Saffar, S., Hanachi, P., Amirabadizadeh, A.R., Esmaeily, H., et al., 2017. hs-CRP is strongly associated with coronary heart disease (CHD): A data mining approach using decision tree algorithm. Comput. Methods Programs Biomed. 141, 105-109.

Thabtah, F.A., Cowling, P.I., 2007. A greedy classification algorithm based on association rule. Appl. Soft Comput. 7 (3), 1102-1111.

Thakur, A., Mishra, V., Jain, S.K., 2011. Feed forward artificial neural network: tool for early detection of ovarian cancer. Sci. Pharm. 79 (3), 493-506.

Thomas, M., Das, M.K., Ari, S., 2015. Automatic ECG arrhythmia classification using dual tree complex wavelet based features. AEU Int. J. Electron. Commun. 69 (4), 715-721.

UC Irvine Machine Learning Repository, 2017. [online] [cit. 2017-11-12]. Available from: http://archive.ics.uci.edu/ml

World Health Organization, 2017a. Cancer. . [online] [cit. 2017-02-13]. Available from: http://www.who.int/mediacentre/factsheets/fs297/en/.

World Health Organization, 2017b. Cardiovascular Diseases (CDV's). . [online] [cit. 2017-05-15]. Available from: http://www.who.int/mediacentre/factsheets/ fs317/en/.

World Health Organization, 2017c. Hepatitis C. . [online] [cit. 2017-10-15]. Available from: http://www.who.int/mediacentre/factsheets/fs164/en/.

Wu, X., Kumar, V., Quinlan, J.R., Ghosh, J., Yang, Q., Motoda, H., et al., 2008. Top 10 algorithms in data mining. Knowl. Inf. Syst. 14 (1), 1-37.

Wu, Y., Wu, Y., Wang, J., Yan, Z., Qu, L., Xiang, B., Zhang, Y., 2011. An optimal tumour marker group-coupled artificial neural network for diagnosis of lung cancer. Expert Syst. Appl. 38 (9), 11329-11334.

Yau, T., Tang, V.Y., Yao, T.-J., Fan, S.-T., Lo, C.-M., Poon, R.T., 2014. Development of Hong Kong Liver Cancer staging system with treatment stratification for patients with hepatocellular carcinoma. Gastroenterology 146 (7), 1691-1700 (e1693). 